\title{
The visual evoked potential in acute primary angle closure glaucoma
}

\author{
KEITH W MITCHELL, CHRISTOPHER M WOOD, JOHN W HOWE, \\ WILLIAM H CHURCH, GEORGE T H SMITH, AND STEPHEN R SPENCER \\ From the Regional Medical Physics Department and University Department of Ophthalmology, Royal Victoria \\ Infirmary, Newcastle upon Tyne
}

SUMMARY Visual evoked potentials (VEPs) were elicited from 29 patients who had experienced a previous attack of acute primary angle closure glaucoma. The VEPs were shown to be abnormal in at least one of the measures (latency, amplitude, contrast threshold, or slope) in $72.4 \%$ of affected eyes, whereas only $41.4 \%$ indicated obvious optic nerve damage. It is notable that $48.1 \%$ of fellow eyes with no (known) history of acute pressure rise also showed some form of VEP abnormality. The possible pathophysiological mechanisms operating in both affected and fellow eyes are discussed. It is concluded that, despite the presence of possible artefactual influences, the results probably reflect the presence of primary angle closure glaucoma.

The pattern electroretinogram (PERG), visual evoked potential (VEP), and contrast sensitivity as assessed by psychophysical (subjective) or electrophysiological (objective) methods have all been shown to be affected by primary open angle glaucoma (POAG) and to a lesser extent by ocular hypertension $(\mathrm{OH}){ }^{1-37}$ While the effect of artificially induced acute intraocular (IOP) rises has been studied in humans, ${ }^{38-40}$ to our knowledge there has been no research into the effect of acute primary angle closure glaucoma (PACG) on electrophysiological potentials or contrast sensitivity. A variety of field defects have been noted in acute PACG, ${ }^{41}$ though clinical evidence of optic nerve damage in successfully treated cases is infrequent, ${ }^{42} 43$ with cataracts possibly being the commonest cause of long-term visual loss. ${ }^{43}$

The aim of this study was objectively to assess visual function in a group of patients with acute PACG by means of the pattern reversal VEP to measure latency and the onset-offset VEP to assess contrast sensitivity. Particular attention was paid to those patients in whom there was no clinical evidence of optic nerve damage.

Correspondence to Dr K W Mitchell, University Department of Ophthalmology, Pavilion Two, Royal Victoria Infirmary, Queen Victoria Road, Newcastle upon Tyne NE1 4LP.

\section{Material and methods}

PATIENTS AND CONTROLS

Patients were included in this study if they had had an episode of acute PACG which had been successfully treated, usually by initial medical therapy followed by definitive surgery or laser treatment. Those with other coexisting eye or visual pathway pathology or visual acuities of less than $6 / 12$ were excluded. All patients had a full ophthalmic assessment which included Goldmann perimetry and VEP investigation while wearing their optimum optical correction. Of the patients investigated 29 ( 5 male and 24 female) with an average age of 61 years (range 43-81 years) were found to fulfil the requirements. Two had had simultaneous bilateral angle closure; in these cases one eye at random was included in the study. Of the 29 affected eyes 17 had surgical iridectomies, nine had YAG laser iridotomies, and three had primary trabeculectomies. The 27 fellow eyes also had prophylactic treatment: 19 surgical iridectomies and eight YAG laser iridotomies. Retrobulbar or general anaesthesia were used for the surgical procedures. The reassessment was performed an average of two years after the acute attack $(9<1$ year, 11 1-2 years, 6 $2-5$ years, and $3>5$ years). All patients gave their formal consent to participating in the study. 
VEP control data were taken from our database of 68 normal subjects ( 31 male and 37 female) in the older age range, the mean and standard deviation of the group being 61.0 and 8.6 years respectively.

\section{ELECTROPHYSIOLOGY}

The checkerboard stimulus was produced by a video pattern generator (Medelec) on a high quality TV monitor (Barco). In the first part of the test the pattern reversal mode of stimulation was used, checksize being $50^{\prime}$, contrast $95 \%$, and field subtended, $17^{\circ} \times 14^{\circ}$. Mean luminance was maintained constant at $10 \mathrm{Cd} . \mathrm{m}^{-2}$ and reversal rate was 2 per second.

The second part of the test, to measure contrast threshold, was performed with the onset-offset mode of stimulation. Pattern 'on' time was adjusted to be $40 \mathrm{~ms}$ and 'off' time $460 \mathrm{~ms}$, that is, a repetition rate of 2 per second. Check size was 19 ' where corrected visual acuity was $\geqslant 6 / 9$ and $25^{\prime}$ where visual acuity was $<6 / 9 \geqslant 6 / 12$. Recordings were made at four or five discrete contrast levels in the range $5 \%$ to $80 \%$, the patients being given short periods of rest in between each measurement to minimise fatigue effects.
Silver/silver chloride disc electrodes were attached to the scalp in the following positions ${ }^{44}$ : active $-\mathrm{Oz}$, reference $\mathrm{Cz}$, earth $-\mathrm{Pz}$. Electrode impedances were measured prior to the test, these being $<2 \mathrm{kohm}$ in both active and reference leads. A Medelec electrophysiological recording unit was used to amplify, average, and store the evoked potentials. The amplifier bandwidth was set to $0 \cdot 8-80 \mathrm{~Hz}$, and either 64 or 128 epochs of 300 ms duration were averaged depending on signal amplitude. Two averages were obtained for each stimulus condition to check for consistency, and quantitative analysis was performed on the average of these two.

The latency of the ' $P 100$ ' component ${ }^{45}$ was measured in all investigations. With respect to amplitude a peak-peak amplitude measure was adopted. In the case of the pattern reversal VEPs it was that between P100-N150, in those to onset-offset it was between components $\mathrm{CI}$ and $\mathrm{CII} .{ }^{4647}$ Monocular stimulation was adopted in all investigations, the subject maintaining fixation on a small LED marker attached to the centre of the screen (this being checked during the investigation by closed

Table 1 Result correlation

\begin{tabular}{|c|c|c|c|c|c|c|c|c|c|c|c|}
\hline & \multicolumn{4}{|l|}{ Clinical } & \multicolumn{7}{|l|}{$V E P$} \\
\hline & $\begin{array}{l}\text { Ant. } \\
\text { segment }\end{array}$ & $P A S$ & $\begin{array}{l}\text { Field } \\
\text { loss }\end{array}$ & $\begin{array}{l}\text { Disc } \\
\text { cupping }\end{array}$ & Lat. & & $\begin{array}{l}\text { Lat. } \\
\text { diff. }\end{array}$ & $\begin{array}{l}\text { Amp. } \\
\text { diff. }\end{array}$ & Threshold & $\begin{array}{l}\text { Threshold } \\
\text { diff. }\end{array}$ & $\begin{array}{l}\text { Slope } \\
\text { diff. }\end{array}$ \\
\hline 1 & $*$ & $*$ & & & & & & & & & \\
\hline 2 & $*$ & $*$ & & & & & $*<$ & $*>$ & & & \\
\hline 3 & $*$ & $*$ & & $*$ & $* * \mathrm{f}$ & i & & & & & \\
\hline 5 & $*$ & $*$ & & & $* * \mathrm{f}$ & 1 & $*$ & & $* * \mathbf{f} \quad \mid$ & $*$ & \\
\hline 6 & $*$ & & & & & : & & $*$ & $* \mathrm{f}$ & & $*$ \\
\hline 7 & * & $*$ & & & & $:$ & & & 1 & & $*>$ \\
\hline 8 & $*$ & $*$ & * & $*$ & & ; & & & $* * \mathrm{f}$ & & \\
\hline 9 & $*$ & & & & & 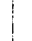 & $*<$ & $*>$ & & & \\
\hline $10(\mathrm{Bi})$ & $*$ & $*$ & $*$ & & $* * \mathrm{f}$ & 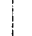 & & & & & \\
\hline 11 & & $*$ & & $*$ & & i & & & & & \\
\hline 12 & $*$ & & & & & 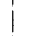 & & & 1 & & \\
\hline 14 & * & $*$ & $*$ & & & 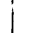 & & & 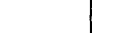 & & * \\
\hline 15 & $*$ & $*$ & $*$ & & & 1 & & & $* * \mathrm{f}$ & & \\
\hline 16 & $*$ & & $*$ & $*$ & $*$ & 1 & $*$ & $*$ & $*$ & $*$ & $*>$ \\
\hline 17 & $*$ & $*$ & $*$ & & $*$ & 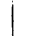 & $*$ & & $*$ & $*$ & $*>$ \\
\hline 18 & & $*$ & & & $* \mathbf{f}$ & $!$ & $*<$ & & & & \\
\hline 19 & $*$ & & & & & 1 & & & & & \\
\hline 20 & $*$ & $*$ & $*$ & & & ! & & & & & $*>$ \\
\hline 21(Bi) & $*$ & $*$ & $*$ & $*$ & & & $*$ & & & & \\
\hline 22 & & & & & & , & $*$ & & 1* & $*$ & \\
\hline 23 & $*$ & & & & $\cdot * * \mathrm{f}$ & & & & ! & & \\
\hline 24 & $*$ & & $*$ & $*$ & $* * \mathrm{f}$ & & & $*$ & $* * \mathrm{f}$ & & $*>$ \\
\hline 25 & $*$ & & & & $* \mathbf{f}$ & & $*<$ & $*>$ & $*$ & $*$ & $*>$ \\
\hline 26 & & & & & & & & & & & $*>$ \\
\hline 27 & & & & & $* * \mathrm{f}$ & & $*<$ & & & & \\
\hline 28 & $*$ & $*$ & $*$ & $*$ & $*$ & & & & & & \\
\hline 29 & $*$ & & & & & & & & & & \\
\hline
\end{tabular}

*Significantly affected. ${ }^{* *}$ Fellow eye also affected. $>=$ Value greater than. $<=$ Value less than. ${ }^{*} \mathrm{f}=$ Fellow eye significantly affected. Lat. $=$ latency. Amp. $=$ amplitude. Diff. $=$ difference $. \mathrm{Bi}=$ bilateral angle closure . 

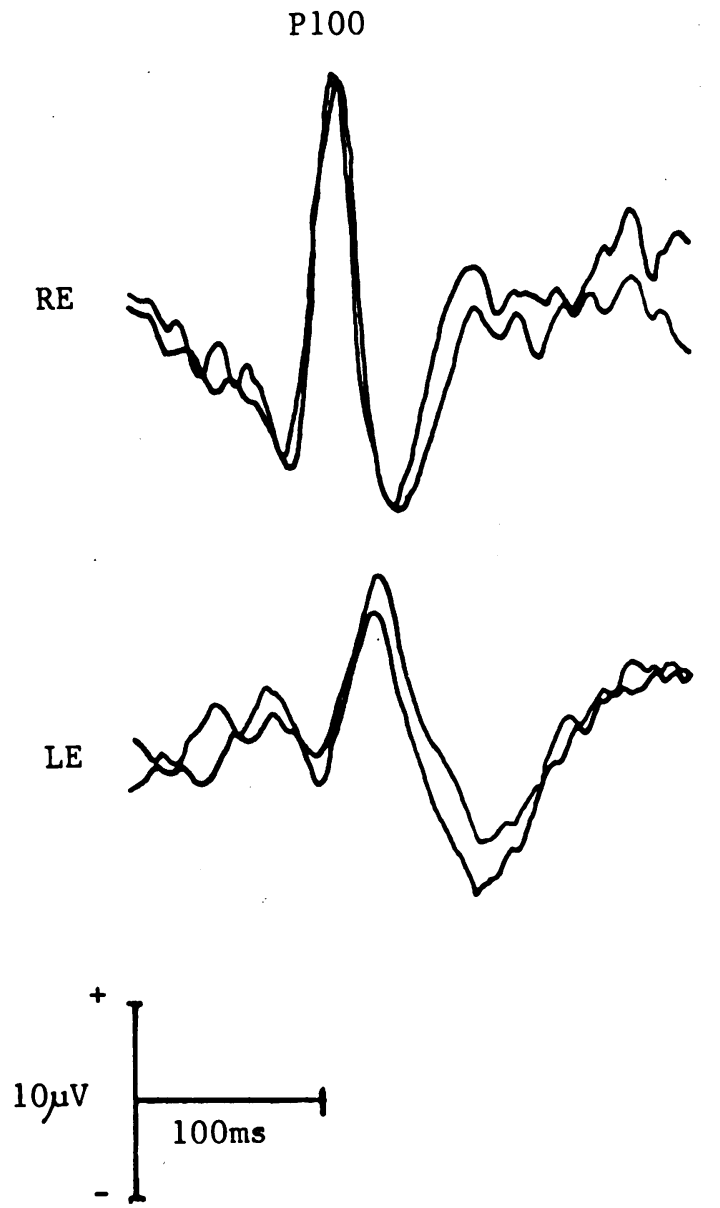

Fig. 1 Pattern reversal VEPs from patient 16, who had previously experienced an acute attack of PACG in the left eye.

circuit television). The non-stimulated eye was occluded with a patch. Before the test the subject was preadapted to the luminance of the blank screen for 5 minutes, which was the only source of illumination in an otherwise darkened room. The investigation was concluded with the measurement of the subject's pupil diameter under experimental conditions.

\section{STATISTICS}

In the establishment of control ranges for absolute VEP values data from one eye in each individual were selected at random. ${ }^{48}$ This procedure was also adopted for the two patients who had undergone a bilateral attack of PACG. In the other 27 patients data from the 'affected' eye were chosen for analysis. With regard to interocular differences, the magnitude of this difference was used in the analyses.
Where the effect of pathology was assumed to produce excursions from normality in one direction only, for example latency increase, a single-tailed Student's $t$ test analysis was adopted and the level of statistical significance set at the $1 \%$ level $(p \leqslant 0 \cdot 01)$. If data distributions were observed to be markedly different in two groups being compared, an F test of variance ratio was performed, and, if significant, a correction $^{49}$ was applied to the number of degrees of freedom (df) being denoted in the analyses by *

\section{Results}

CLINICAL

Twenty-six out of 29 affected eyes had either iris atrophy or peripheral anterior synechiae (PAS), while only two of 27 fellow eyes had PAS. Clinical evidence of optic nerve damage was present in $12 / 29$ affected eyes, seven having optic disc changes and 10 having field defects, which were predominantly in the upper hemisphere (7/10). None of the 27 fellow eyes showed significant changes in the optic disc or visual field.

\section{ELECTROPHYSIOLOGY}

Pattern Reversal VEPs

VEPs elicited from the right and left eyes of female patient 16 (Table 1), who had an acute PACG episode in the left eye, are shown in Fig. 1. The form of the right eye's response was typical of that elicited to this stimulus mode, the clear positive ' $\mathrm{P} 100$ ' component being observed, which in general has monotonic form and nominal latency of $100 \mathrm{~ms}$. In comparison, the response from the left eye was delayed and attenuated.

In Fig. 2 scattergrams of P100 latency for controls and the patients' affected and fellow eyes are shown in respective columns. As VEP latency is influenced by age,,$^{23} 50$ the data were divided into two age-cells, $40-61$ yr and 62-85 yr, to minimise this confounding factor and are illustrated respectively in Fig. 2(a) and (b). Thirty-seven and 31 of the controls fell into the younger and older age cells, respectively. For patients the corresponding numbers were 12 and 17. In comparison with control data the patient values showed a clear difference in distribution, which, interestingly, was the case not only for affected eyes but for fellow eyes too. Statistical analysis (the results of which are shown above each column of the scattergrams) essentially confirmed this visual impression, although the difference in means in the older age cell was not significant. (It is probable that this was due to broader data distribution and consequent statistical limitations rather than the absence of a real effect.) Upper confidence limits (cl) at the $99 \%$ 
(a)

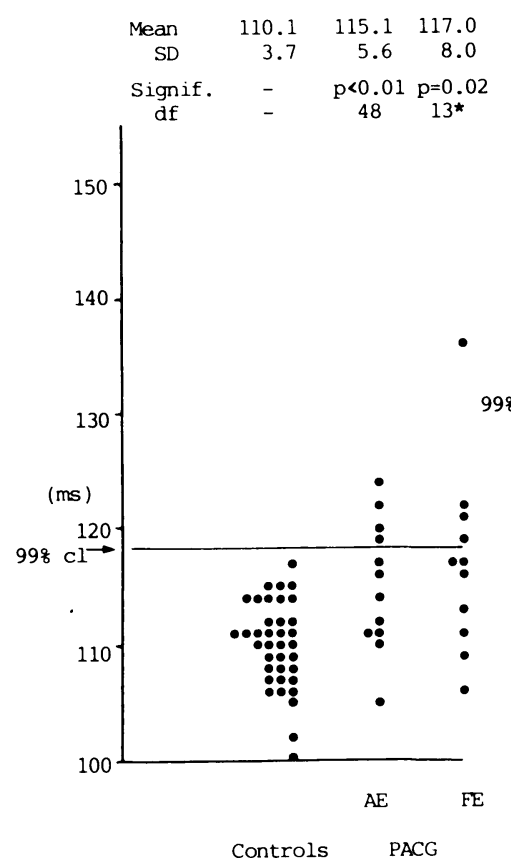

points were determined from control data and are shown drawn on each diagram, these being $118.7 \mathrm{~ms}$ for the younger group and $130.2 \mathrm{~ms}$ for the older. Thus it can be seen that in nine of 29 affected eyes (four and five of the younger and older groups, respectively) and seven of 27 fellow eyes (four and three, respectively) latencies were significantly delayed.

An important feature for investigation when monocular VEPs are elicited are interocular differences, which of course have much reduced intersubject variability in comparison to absolute measures. In Fig. 3(a) interocular latency differences are shown plotted for control and patient groups. This quantity is not age dependent, so all 68 controls and 27 unilateral PACG patients are presented on the same scattergram. A difference in distribution is, again, evident and confirmed by corresponding statistical analysis. With regard to individual cases, 10 of 27 (and one of the two bilateral cases, not displayed), were at or above the upper cl of $5.9 \mathrm{~ms}$. Note, however, that five of the 10 had longer latencies in favour of the fellow eye.

As to VEP amplitude, no differences were observed in comparison with controls. However, interocular differences did appear to show some effect (see Fig. 3(b)), but the difference in group means was found to be not quite significant $(0.02>$ $p>0 \cdot 01$ ). Individually eight of 27 were significant (b)

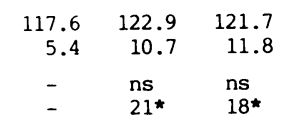

Fig. 2 Scattergrams of PIOO latency from controls and $P A C G$ patients in the 40-61 yrage-cell (a), and the 62-85 yr age-cell (b). See text for meaning of asterisk in Figs. $2,3,5$, and 6 . (upper $\mathrm{cl}=4.4 \mu \mathrm{V}$ ), three of the eight having lower amplitudes in the fellow eye.

ONSET-OFFSET VEPS

Onset-offset VEPs from the left and right eyes of patient 16 are illustrated in Fig. 4(a). These responses, and in particular the CI-CII components, show a progressive reduction in amplitude as stimulus contrast is reduced. However, it can be seen that this attenuation is more pronounced in the left eye as compared with the right eye, an effect further illustrated when CI-CII amplitude is plotted against log contrast (Fig. 4(b)) and least squares regression lines are drawn through the data. A separation of the two regression lines is evident, and a difference in contrast threshold predicted. Extrapolation of the regression lines to the abscissa to determine threshold confirmed the increase in the left eye $(6.0 \%)$ as compared with the right eye $(1 \cdot 8 \%)$ (a full discussion of contrast threshold determination by this method is given elsewhere ${ }^{37}$ ).

This procedure was performed on all control subjects and patients, and relevant threshold scattergrams are illustrated in Fig. 5(a). (Note that the usual convention of showing decreasing threshold, namely, increasing sensitivity, in the upwards direction on the diagram, is adhered to.) There appears to be a shift to higher thresholds in the patient data, notwithstanding the fact that $\log$ scaling inevitably produces a 
(a)
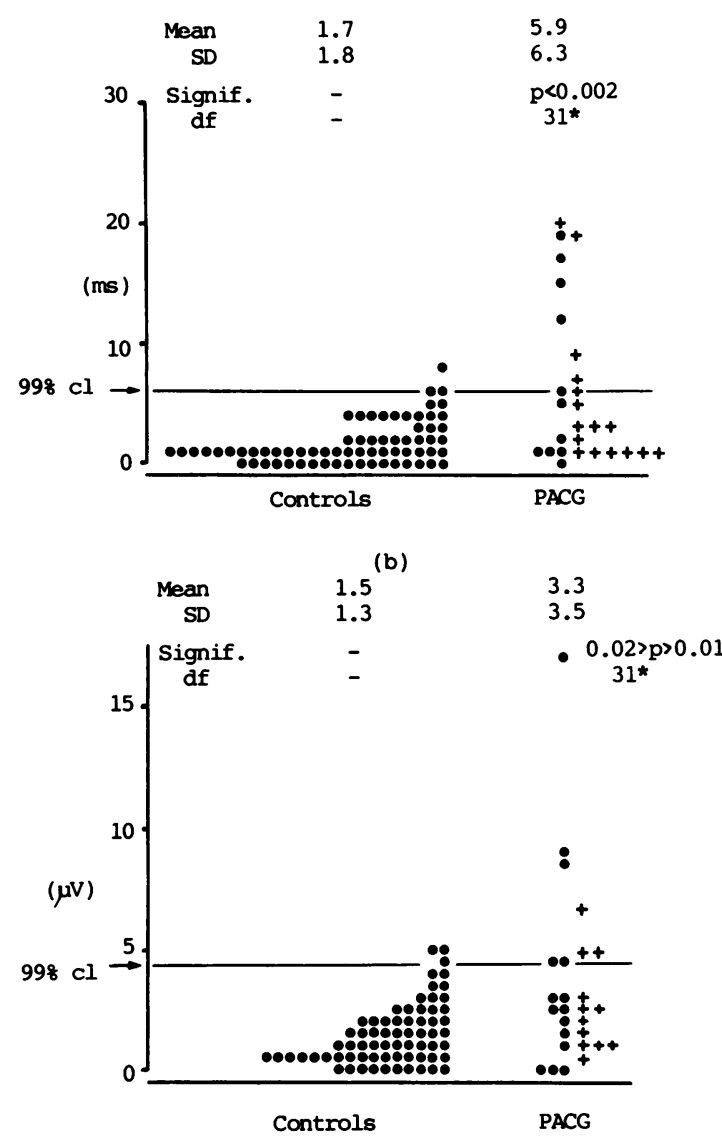

Fig. 3 Scattergrams of interocular latency (a) and interocular amplitude (b) in controls and $P A C G$ patients. Note: symbol + denotes larger value in unaffected eye in diagram (a) and lesser value in unaffected eye in diagram (b).

diagrammatic compression. Statistical analysis revealed that patient means were significantly different from control means not only for affected eyes but for fellow eyes as well. In relation to individual cases, nine of 29 affected eyes and five of 27 fellow eyes were above the upper cl of $4 \cdot 8 \%$.

Interocular threshold differences are displayed in Fig. 5(b). Although patient data appear to be biased towards higher values, statistically this was not quite significant. Individually, six of 27 cases showed an increase above the upper cl of $2.5 \%$, all six showing the higher value in the affected eye.

The last evoked potential feature of interest is that of the slope of the regression line. This measure, however, showed large interindividual variability and did not reach significance in the patient group.
Interocular measures, on the other hand, did show differences in distribution (Fig. 6), a feature confirmed by the statistically disparate group means. In terms of individual significances, nine of 27 equalled or exceeded the upper cl of $3 \cdot 3 \mu \mathrm{V}$ (log unit) ${ }^{-1}$, and, of these, seven had the higher slope for the affected eye.

\section{PUPIL SIZE}

The pupillary diameter was observed to be significantly different in the affected eyes of patients as compared with controls (patient mean $6 \cdot 1$, SD 1.8 $\mathrm{mm}$; control mean 3.9, SD $0.9 \mathrm{~mm}$; p $<0.001$, df 95). With regard to fellow eyes, no difference was observed (patient mean $3 \cdot 8$, SD $0.8 \mathrm{~mm}$ ).

\section{SUMMARY OF RESULTS}

A summary of the significant clinical and electrophysiological findings in each patient is shown in Table 1. In total, 24 of 29 patients $(82.8 \%)$ had some form of VEP abnormality in either eye. With respect to affected eyes, 21 of $29(72.4 \%)$ had abnormalities, and for fellow eyes the figure was 13 of $27(48 \cdot 1 \%)$. In the affected eyes of 17 patients who had either clinical signs or abnormalities confined to the anterior segment, $12(70 \cdot 6 \%)$ had some form of VEP abnormality. For the other 12 who had some form of optic nerve involvement (that is, field defects and/or disc cupping/pallor), $11(91.7 \%)$ were detected in one way or another by the VEP.

\section{Discussion}

An accurate assessment of visual function in patients who have suffered an attack of acute PACG is fraught with difficulty. The group as a whole is elderly, and other coexisting eye or visual pathway disease is frequently present and can complicate any assessment of optic nerve function..$^{42} 51$ We specifically excluded patients with such pathology as well as those with poor vision to minimise any confounding influence on the VEP. In eyes with manifest optic nerve pathology (disc or field changes) a high correlation with VEP abnormalities $(91.7 \%)$ was noted. In affected eyes with clinically no evidence of optic nerve damage (normal fields and discs) $70.6 \%$ showed some form of VEP abnormality, indicating the presence of covert optic nerve pathology.

These finding occurred despite the presence of two important artefacts which could have had the effect of concealing the full level of optic nerve damage. Firstly, the electrode montage used allows the cortical generator sites representing inferior field to dominate the full field VEP, whereas the majority of the field defects $(7 / 10)$ in this study occurred in the superior field. In POAG this effect has been shown to 
(a)

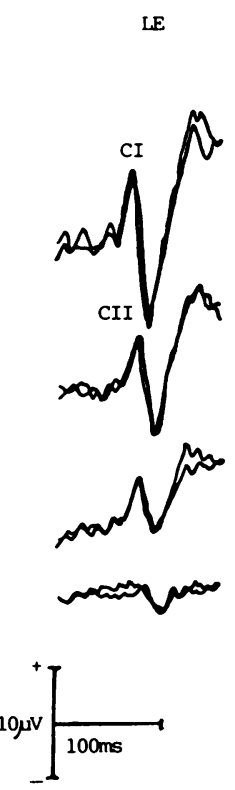

(b)

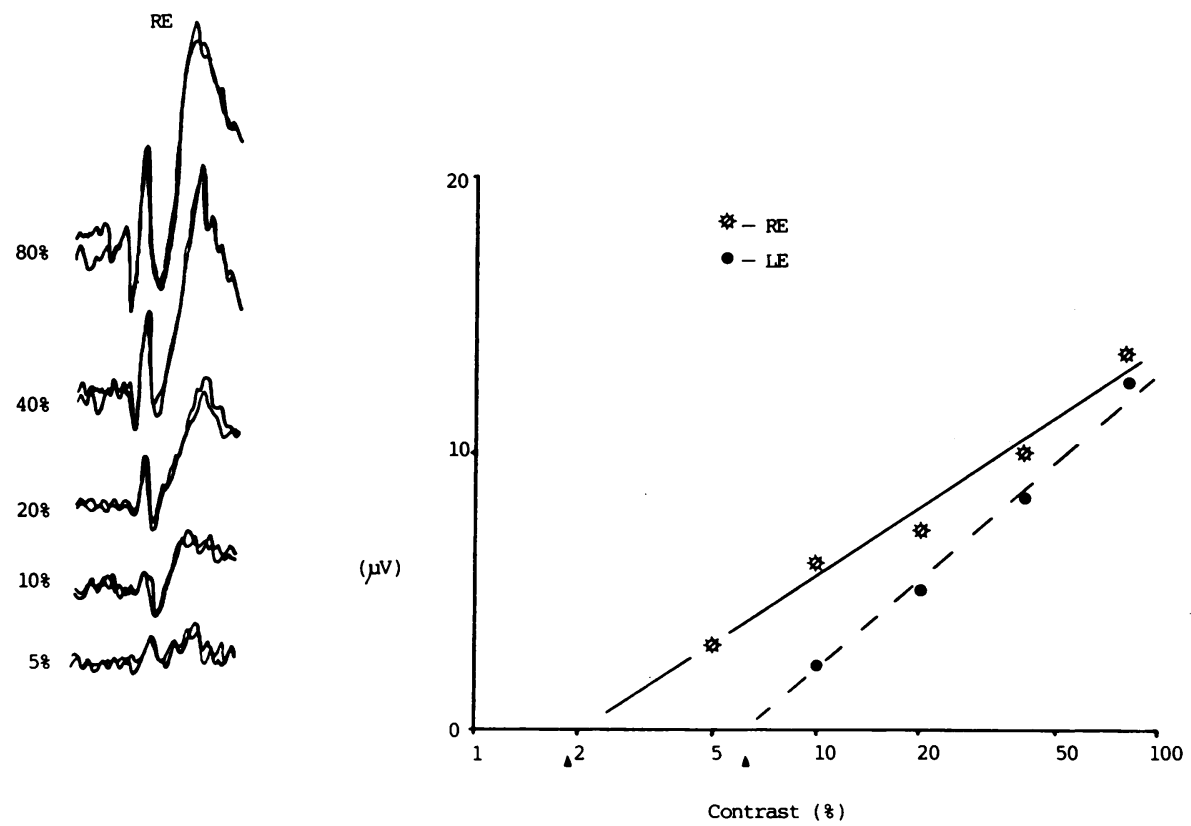

Fig. 4 Onset-offset VEPs from patient 16 to different contrast levels (a) and the CI-CII amplitude-log ${ }_{10}$ contrast plot of these data in (b).

reduce dramatically the VEP detection rate in patients with predominantly upper field loss. ${ }^{23}$ Secondly, the influence of increased pupil size due to sphincter paresis in affected eyes must also be considered. This increases retinal illumination, which has the effect of decreasing VEP latency ${ }^{52}$ and enhancing contrast sensitivity, an effect which, again, serves to underestimate the level of optic nerve damage. In spite of these influences, overall $72 \cdot 4 \%$ of affected eyes showed some form of electrophysiological abnormality, suggesting that significant optic nerve damage is extremely common after acute PACG and strongly implicating PACG as the cause of such optic nerve dysfunction.

The VEP changes in PACG are similar to those found in POAG, though one feature differs-the regression line slope of the amplitude-contrast plot. This is a suprathreshold measurement related to the difference in the luminance of the individual squares (spatial contrast) rather than the quality of the border between them, as it has been observed that optic blurring does not modify it but merely results in increased threshold. ${ }^{37}$ At a retinal level this is likely to be related to the spike discharge rate of ganglion cells with centre-surround antagonistic properties. ${ }^{23}$ In a study of patients with apparently unilateral $\mathrm{POAG}^{23} 70 \cdot 6 \%$ of 'affected' eyes were shown to have significantly lower slopes in comparison to their 'unaffected' eyes. It was argued that glaucoma had the effect of not only increasing threshold but also of suppressing suprathreshold firing, thereby decreasing the slope. However, in this study on PACG the changes were in the opposite sense - that is, $77.8 \%$ of our patients who had a significant interocular slope difference did so with the higher value in the affected eye. These findings can be explained if PACG has its main effect on threshold, affecting suprathreshold firing secondarily and to a lesser degree. The effect of raising threshold with unaltered suprathreshold firing would have the effect of increasing the slope. However, such conclusions have to be modified to some degree by the fact that they are based on interocular data and therefore assumed an 'unaffected' state for the fellow eye, an assumption not entirely justifiable, as we found $48 \cdot 1 \%$ of these eyes showed an abnormality.

To comprehend fully the possible mechanisms of optic nerve damage in the two conditions it is necessary to be aware of the cellular layout in the anterior visual pathway. In primates retinal ganglion cells can be divided into two types - the magnocellular pathways and the parvocellular pathways. ${ }^{53}$ The magnocellular pathways have large receptive fields, are most sensitive to low spatial-frequency gratings 


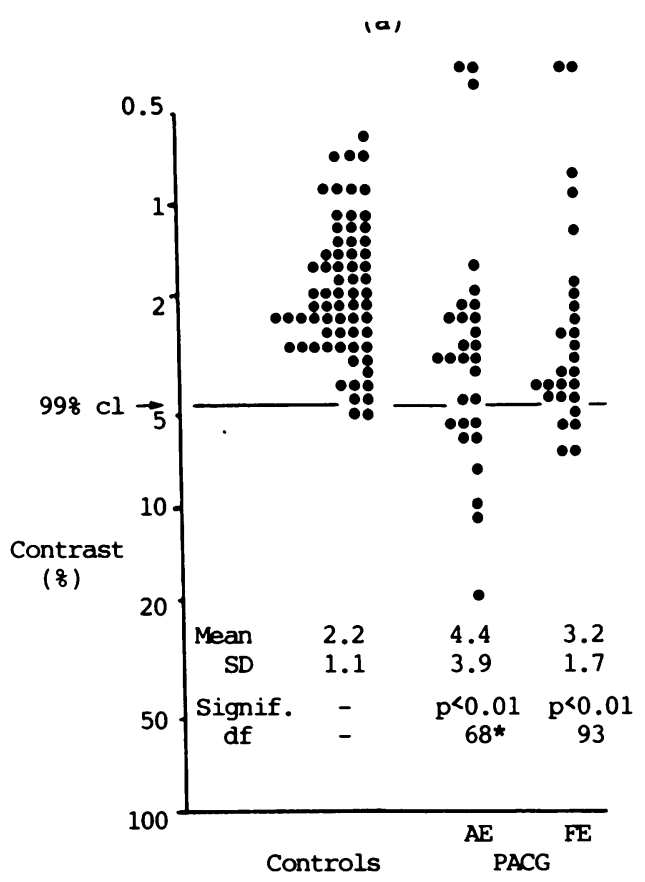

(b)

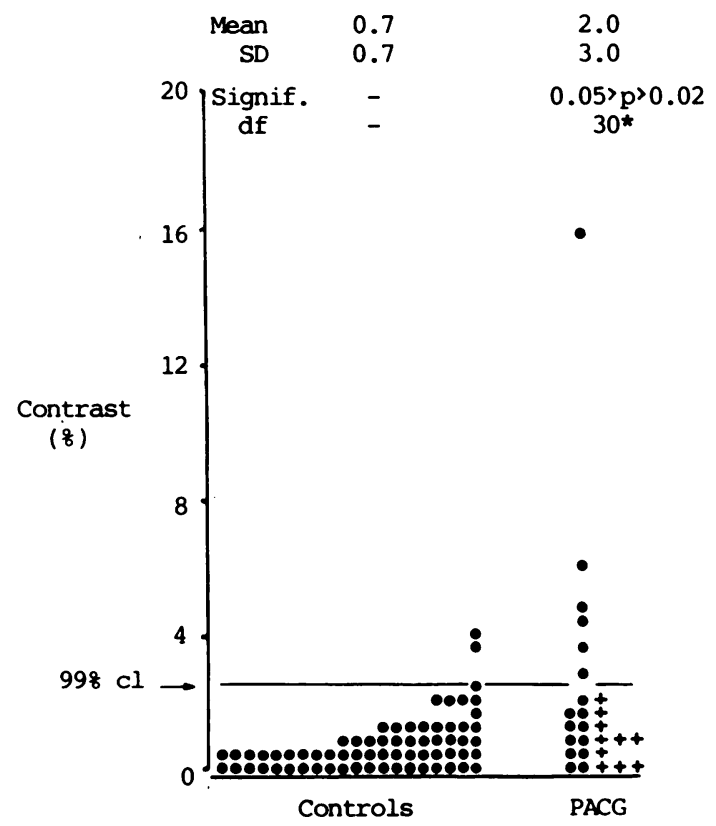

Fig. 5 Scattergrams of contrast threshold (a) and interocular threshold differences (b), in controls and PACG patients. Note: symbol + in diagram (b) denotes larger value in unaffected eye.

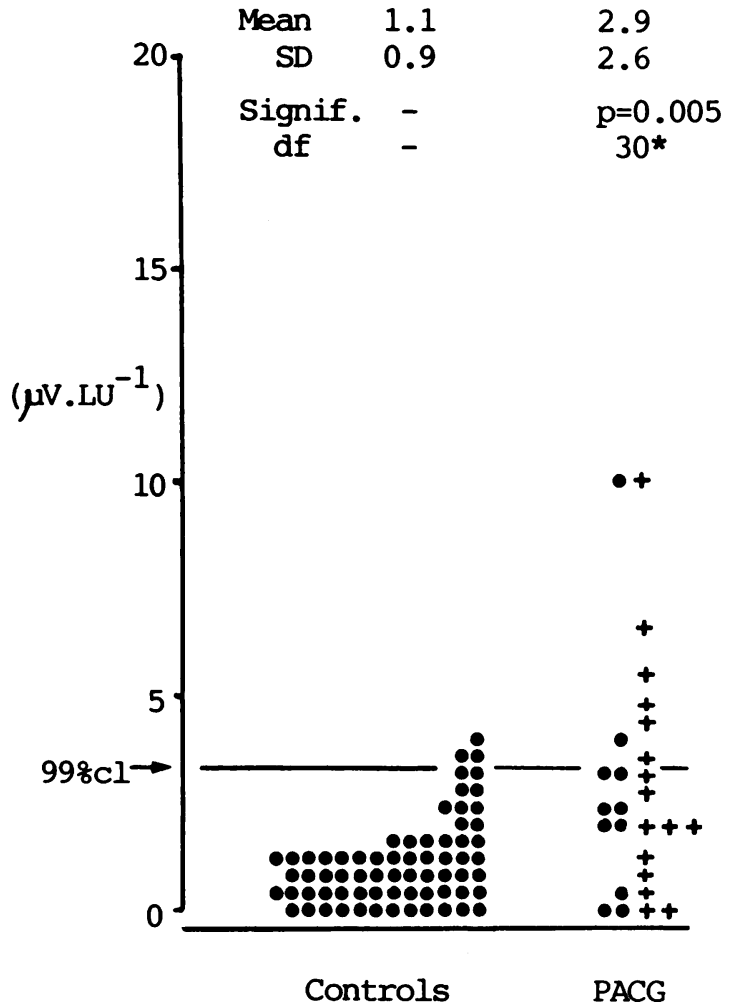

Fig. 6 A scattergram of interocular slope difference in controls and PACG patients. Note: symbol + denotes lesser value in unaffected eye.

(or large checks), function near to threshold, and synapse with large cells in the lateral geniculate body. These pathways consist of both $\mathrm{X}$ and $\mathrm{Y}$ cells, and are more highly contrast sensitive than the parvocellular pathways, which consist almost exclusively of X cells and synapse in the lateral geniculate body on small cells. The discovery in normal humans of a steadystate (on-off) VEP with low and high contrast limbs is in keeping with this theory of separate pathways (the low contrast sensitivity parvocellular and the high contrast sensitivity magnocellular) and suggests these pathways exist in humans..$^{54}$

There is now both electrophysiological ${ }^{55}$ and anatomical ${ }^{56}$ evidence from experimentally induced glaucoma in primates that it is the $\mathrm{Y}$ magnocellular pathways which are the first affected by chronic increase of IOP. Our findings in PACG are in keeping with damage occurring to pathways which are highly contrast sensitive and function near threshold. This is synonymous with damage to the $\mathrm{Y}$ cell magnocellular pathway. Presumably with acute PACG the insult is relatively short-lived and changes 
are confined to this group of cells. However, with POAG the situation is different, in that we are dealing with a progressive condition. Thus while the initial damage may occur in the $\mathrm{Y}$ cell magnocellular pathways, as the disease process progresses it will embrace the other pathways (X cell magnocellular and eventually parvocellular). So though the fundamental modes of optic nerve damage in POAG and PACG may be similar, the magnitude of the insult, in terms of the level of optic nerve dysfunction (as determined by the level of IOP increase and its duration) could still be different. Thus we might expect, as we have found here, the VEP to show similar changes in the two conditions, but with subtle differences indicative of differing levels of damage.

Finally with regard to the VEP abnormalities found in the apparently unaffected fellow eyes, we can only speculate on the cause of this. Mapstone and Clarke $^{57}$ proposed the theory that PACG occurs in a 'sick eye in a sick body', with the acute attack being only a single episode in the disease process. ${ }^{58}$ Our findings of optic nerve dysfunction in fellow eyes in the absence of any definite history of IOP rise would appear to add support to their argument and suggest that the optic nerves are either abnormal as part of the disease process or perhaps more susceptible than normal eyes to minor variations in IOP. However, we must concede that as all measurements were performed after the fellow eyes had undergone prophylactic surgery or laser treatment, it is possible that in some cases the optic nerve damage was due to such factors as injury from the retrobulbar injection, ischaemic optic neuropathy due to general anaesthesia, or undetected acute IOP rise following YAG laser treatment.

The authors are grateful to Mrs Karen Seed, senior medical physics technician, who skilfully elicited a large proportion of the evoked potential data in this study.

\section{References}

1 Ermers HJM, de Heer LJ, Van Lith GHM. VECP's in patients with glaucoma. Doc Ophthalmol Proc Ser 1974; 4: 387-93.

2 Cappin JM, Nissim S. Visual evoked responses in the assessment of field defects in glaucoma. Arch Ophthalmol 1975; 93: 9-18.

3 Abe H, Iwata K. Checkerboard pattern reversal VER in the assessment of glaucomatous field defects. Nippon Ganka Gakkai Zasshi 1976; 80: 829-41.

4 Galloway NR, Barber C. The transient pattern onset VEP in glaucoma. Doc Ophthalmol Proc Ser 1980; 27: 95-101.

5 Krogh E. VER in intraocular hypertension. Acta Ophthalmol (Kbh) 1980; 58: 929-32.

6 Spekreijse H. Pattern evoked potentials: principles, methodology and phenomenology. In: Barber C, ed. Evoked potentials. Lancaster: MTP Press, 1980: 55-74.

7 Huber C. Pattern evoked cortical potentials and automated perimetry in chronic glaucoma. Doc Ophthalmol Proc Ser 1981; 27: 87-94.

8 Howe JW, Mitchell KW. Visual evoked cortical potential in patients with glaucoma and suspected glaucoma. Res Clin Forums 1982; 4: 41-53.
9 Mitchell KW, Howe JW. Assessment of changes in VECP latency and spatial contrast sensitivity in patients with chronic glaucoma and suspected glaucoma. Doc Ophthalmol Proc Ser 1982; 31: 445 .

10 Sokol S, Domar A, Moskowitz A, et al. Pattern evoked potential latency and contrast sensitivity in glaucoma and ocular hypertension. Doc Ophthalmol Proc Ser 1981; 27: 79-86.

11 Towle VL, Moskowitz A, Sokol S, et al. The visual evoked potential in glaucoma and ocular hypertension: effects of check size, field size and alternation rate. Invest Ophthalmol Vis Sci 1983; 24: 175-83.

12 Atkin A, Bodis-Wollner I, Podos SM, et al. Flicker threshold and pattern VEP latency in ocular hypertension and glaucoma. Invest Ophthalmol Vis Sci 1983; 234: 1524-8.

13 Bobak P, Bodis-Wollner I, Harnois C, et al. Pattern electroretinograms and visual evoked potentials in glaucoma and multiple sclerosis. Am J Ophthalmol 1983; 95: 72-83.

14 Wanger P, Persson HE. Pattern-reversal electroretinograms in unilateral glaucoma. Invest Ophthalmol Vis Sci 1983; 24: 749-53.

15 Howe JW, Mitchell KW. Simultaneous recording of pattern electroretinogram and visual evoked cortical potential in a group of patients with chronic glaucoma. Doc Ophthalmol Proc Ser 1984; 40: 101-8.

16 Porciatti V, von Berger GP. Pattern electroretinogram and visual evoked potential in optic nerve disease: early diagnosis and prognosis. Doc Ophthalmol Proc Ser 1984; 40: 117-26.

17 Ponte F, Anastasi M, Lauricella M. Visual evoked potentials and visual field evolution after normalisation of intraocular pressure in glaucoma. Proc Ophthalmol Proc Ser 1984; 40: 257-64.

18 Follman P, Kerenyi A, Vitrai J, et al. Assessment of optic nerve function by visual evoked potential recordings in the diagnosis of glaucoma. Doc Ophthalmol Proc Ser 1984; 40: 265-71.

19 Papst N, Bopp M, Schnaudigel OE. Flash and pattern electroretinograms in advanced glaucoma. Klin Monatsbl Augenheilkd 1984; 184: 199-201.

20 Van Lith GHM, Ringens P, de Heer LJ. Pattern electroretinogram and glaucoma. Dev ophthalmol 1984; 9: 133-9.

21 Wanger P, Persson HE. Pattern-reversal electroretinograms in ocular hypertension. Doc Ophthalmol 1985; 61: 27-31.

22 Howe JW, Mitchell KW. Visual evoked cortical potential to paracentral retinal stimulation in chronic glaucoma, ocular hypertension and an age-matched group of normals. Doc Ophthalmol 1986; 63: 37-44.

23 Mitchell $\mathrm{KW}$. The visual evoked potential in the differential diagnosis of ocular hypertension and chronic simple glaucoma. $\mathrm{PhD}$ thesis. University of Newcastle upon Tyne. 1987.

24 Abe H, Hasegawa S, Iwata K. Contrast sensitivity and pattern visual evoked potential in patients with glaucoma. Doc Ophthalmol 1987; 65: 65-70.

25 Holder GE. Significance of abnormal pattern electroretinography in anterior pathway dysfunction. Br J Ophthalmol 1987; 71: $166-71$.

26 Trick GL. Pattern reversal retinal potentials in ocular hypertensives at high and low risk of developing glaucoma. Doc Ophthalmol 1987; 65: 79-86.

27 Porciatti V, Falsini B, Brunori S, et al. Pattern electroretinogram as a function of spatial frequency in ocular hypertension and early glaucoma. Doc Ophthalmol 1987; 65: 349-56.

28 Arden GB, Jacobson JJ. A simple grating test of contrast sensitivity: preliminary results indicate value in screening for glaucoma. Invest Ophthalmol Vis Sci 1978; 17: 23-32.

29 Atkin A, Bodis-Wollner I, Wolkstein M. Abnormalities of central contrast sensitivity in glaucoma. Am J Ophthalmol 1979; 88: 205-11.

30 Cooper RL, Constable IJ, Terrell A. Mass screening for glaucoma and other eye disease using the Arden grating test Aust J Ophthalmol 1980; 8: 131-7.

31 Hitchings RA, Powell DJ, Arden GB, et al. Contrast sensitivity gratings in glaucoma family screening. Br J Ophthalmol 1981; 65: 515-7. 
32 Stamper RL, Hsu-Winges C, Sopher M. Arden contrast sensitivity testing in glaucoma. Arch Ophthalmol 1982; 100: 947-50.

33 Vaegan, Halliday BL. A forced-choice test improves clinical contrast sensitivity testing. Br J Ophthalmol 1982; 66: 477-91.

34 Ross JE, Bron AJ, Clarke DE. Contrast sensitivity and visual disability in chronic simple glaucoma. Br J Ophthalmol 1984; 68: 821-7.

35 Motolko MA, Phelps CD. Contrast sensitivity in asymmetric glaucoma. Int Ophthalmol 1984; 7: 45-59.

36 Lundh B. Central contrast sensitivity tests in the detection of early glaucoma. Acta Ophthalmol (Kbh) 1985; 63: 481-6.

37 Howe JW, Mitchell KW. The objective assessment of contrast sensitivity function by electrophysiological means. $\mathrm{Br} J$ Ophthalmol 1984; 68: 626-38.

38 Neetens A, Hendrata Y, Van Rompaey J. Optic pathway action potentials and intraocular pressure rise. Doc Ophthalmol Proc Ser 1981; 27: 103-10.

39 Bartl G. The effects of visual field changes and ocular hypertension on the visual evoked potential. Ann NY Acad Sci 1982; 338: $227-42$.

40 Ulrich WD, Ulrich C. An electrophysiological approach to the diagnosis and treatment of glaucoma. In: Zrenner E, ed. Dev Ophthalmol 1984; 9: 140-6.

41 Harrington DO. The visual fields. St Louis: Mosby, 1970: 181.

42 Radius RL, Maumanee AE. Visual field changes following acute elevation of intraocular pressure. Ophthalmology 1977; 83: 61-8.

43 Douglas GR, Drance S, Schulzer M. The visual field and nerve head following acute angle closure glaucoma. Can J Ophthalmol 1974; 9: 404-7.

44 Jasper HH. Report of a committee of methods of clinical examination in electroencephalography. Electroencephalogr Clin Neurophysiol 1958; 10: 370-5.

45 Halliday AM, McDonald WI, Mushin J. Delayed visual evoked response in optic neuritis. Lancet 1972; i: 982-5.
46 Jeffreys DA, Axford JG. Source locations of pattern-specific components of human visual evoked potentials. I. Component of striate cortical origin. Exp Brain Res 1972; 16: 1-21.

47 Jeffreys DA, Axford JG. Source locations of pattern-specific components of human visual evoked potentials. II. Component of extra-striate cortical origin. Exp Brain Res 1972; 16: 22-40.

48 Ederer F. Refereeing clinical research papers for statistical content (Editorial). Am J Ophthalmol 1985; 100: 735-7.

49 Bailey NTJ. Statistical methods in biology. London: Hodder and Stoughton, 1981: 49-51.

50 Mitchell KW, Howe JW, Spencer SR. Visual evoked potentials in the older population: age and gender effects. Clin Phys Physiol Meas 1987; 8: 317-24.

51 Lyne AJ, Phillips CI. Visual field defects due to opacities in the optical media. Br J Ophthalmol 1969; 53: 119-22.

52 Penne A, Fonda S. Influence of pupillary size on P100 latency time of pattern-reversal VEP. Doc Ophthalmol Proc Ser 1981; 27: 255-62.

53 Kaplan E, Shapley RM. X and Y cells in the lateral geniculate nucleus of macaque monkeys. J Physiol (Lond) 1982; 330: 12543.

54 Bobak P, Bodis-Wollner I, Harnois C, Thornton J. VEP's in humans reveal high and low spatial contrast mechanisms. Invest Ophthalmol Vis Sci 1984; 25: 980-3.

55 Marx MS, Podos SM, Bodis-Wollner I, Lee PY, Wang RF, Severin C. Signs of early damage in glaucomatous monkey eyes: low spatial frequency losses in the pattern ERG and VEP. Exp Eye Res 1988; 46: 173-84.

56 Quigley HA, Hendrickson A. Chronic experimental glaucoma in primates: blood flow study with iodantipyrine and pattern of selective ganglion cell loss. Invest Ophthalmol Vis Sci 1984; suppl 25: 225.

57 Mapstone R, Clarke CV. The prevalence of autonomic neuropathy in glaucoma. Trans Ophthalmol Soc UK 1985; 104: 265-9.

58 Mapstone R. The fellow eye. Br J Ophthalmol 1981; 65: 410-3.

Accepted for publication 6 October 1988. 